УДК: 616.831.9-002+616.002.091+615.032+543.544.5.068.7

DOI: $10.15587 / 2313-8416.2015 .47265$

\title{
ПОРІВНЯЛЬНЕ ДОСЛІДЖЕННЯ КОНЦЕНТРАЦІЇ КЛІНДАМІЦИНУ В ЛІКВОРІ ПРИ ВНУТРІШНЬОВЕННОМУ ТА ІНТРАТЕКАЛЬНОМУ ВВЕДЕННІ У ХВОРИХ НА ТОКСОПЛАЗМОЗНИЙ МЕНІНГОЕНЦЕФАЛІТ
}

\author{
(C) С. П. Борщов \\ Публікація присвячена дослідженню концентрації кліндаміцчину в лікворі хворих при різних способах вве- \\ дення: внутрішньовенному і комбінованому (внутрішньовенне+інтратекальне). Підтверджена безпека \\ інтратекального застосування дози 150 мг. Кліндаміцину + 8 мг. дексаметазону. При інтратекальному \\ введенні 150 мг кліндаміцฺну встановлено статистично достовірне підвищення концентрації препарату \\ в лікворі на період не менше доби
}

Ключові слова: токсоплазмозний менінгоенцефаліт, кліндаміцин, інтратекальне введення, ліквор, концентрація, безпечність, ефективність

There were studied the clindamycin concentrations in cerebrospinal fluid (CSF) of patients with toxoplasmic meningoencephalitis at the different ways of administration: intravenous and combined (intravenous + intrathecal).

Aim of the work: to study the difference of clindamycin concentration in CSF at the intravenous and combined (intrathecal+intravenous) ways of administration of preparation.

Materials and methods: study was carried out at the treatment of 11 HIV-positive patients 27-63 years old (men and women) with toxoplasmic meningoencephalitises.

There was measured the clindamycin concentration in CSF of every patient after intravenous and combined (intrathecal+intravenous) ways of administration of preparation. The determinations of concentration were done by the way of the reverse-phase high-performance liquid chromatography (HPLC) with ultraviolet (UV) detection. Statistic processing of the received data was carried out using the Wilcoxon criterion.

Results of research. There was received the statistically significant increase of clindamycin concentration in CSF of patients in a day after combined (intrathecal+intravenous) administration of preparation comparing with an intravenous administration.

\section{Conclusions.}

1. Intrathecal administration of $150 \mathrm{mg}$. of clindamycin with $8 \mathrm{mg}$. of dexamethasone is safe.

2. Intrathecal administration of $150 \mathrm{mg}$. of clindamycin with $8 \mathrm{mg}$. of dexamethasone in combination with an intravenous administration of preparation leads to statistically significant increase of clindamycin concentration in CSF at least during a day after injection.

3. Intrathecal administration of clindamycin with dexamethasone in offered doses can be recommended for treatment of meningoencephalitises that caused by microorganisms susceptible to clindamycin.

4. If the therapy of toxoplasmic meningoencephalitis was started with an intravenous prescription of clindamycin it is recommended an additional treatment with an intrathecal administration of clindamycin with dexamethasone in offered doses to increase efficiency by creating an effective concentration of preparation in the nidus of infection. 5. Intrathecal methods of therapy must be used by the specialists of the respective qualification

Keywords: toxoplasmic meningoencephalitis, clindamycin, intrathecal administration, cerebrospinal fluid (CSF), concentration, safety, efficiency

\section{1. Вступ}

Токсоплазмоз - одна з найпоширеніших опортуністичних інфекцій у ВІЛ-інфікованих та часто $є$ причиною смерті. ВІЛ-інфіковані, які мають антитіла до Toxoplasma gondii, схильні до високого ризику розвитку токсоплазмозного енцефаліту. Так, в Росії у хворих 3 ВІЛ-інфекцією церебральний токсоплазмоз займає 3-є місце (28,5 \%) після цитомегаловірусної інфекції (35,7\%) і туберкульозу (32,1 \%). У США латентним токсоплазмозом страждають 15-40 \% ВІЛ-інфікованих дорослих, приблизно у третини з них розвивається токсоплазмозний менінгоенцефаліт [1].

Препаратами вибору при лікуванні цієї патології є піриметамін та сульфадіазин, однак в зв'язку 3 відсутністю реєстрації цих препаратів в Україні, а також їх токсичністю, застосовують альтернативні схеми лікування $з$ призначенням кліндаміцину внутрішньовенно крапельно [2]. Кліндаміцин в альтернативних схемах лікування токсоплазмозного менінгоенцефаліту рекомендують також закордонні фахівці [3]. Відомо, що важливим чинником дії препаратів на збудника $\epsilon$ концентрація антибіотика у вогнищі інфекції.

\section{2. Обгрунтування дослідження}

При уважному вивченні оригінальної інструкції до препарату Далацин Ц (діюча речовина - кліндаміцин) зустрічаємо наступне в розділі «Розподіл препарату в організмі»: «Кліндаміцин не проникає у 
спинномозкову рідину, навіть у випадку менінгіту.». Одночасно в тому ж таки документі, нижче: «Показання для застосування. Токсоплазмовий енцефаліт у хворих на СНІД.» [4]. На нашу думку, вирішення питання щодо створення високої концентрації у вогнищі інфекції, а отже ефективності кліндаміцину, при лікуванні токсоплазмозного менінгоенцефаліту, можливо шляхом інтратекального введення препарату. Закордонні фахівці також рекомендують обирати пряме інтратекальне введення препаратів, які не легко проникають в центральну нервову систему, у випадках коли інші ефективні терапевтичні можливості недоступні [5].

Існують повідомлення про ефективне застосування антибіотиків інтратекально за бактерійних менінгоенцефалітів [6-9].

В той же час у доступній науковій літературі нами не знайдено жодного повідомлення про інтратекальне застосування кліндаміцину при лікуванні менінгоенцефалітів, тим більш встановлення концентрації препарату у лікворі за даного способу введення.

В попередніх дослідженнях на тваринах нами встановлено безпечність інтратекального введення кліндаміцину [10], що дозволило перейти до клінічного етапу.

\section{3. Мета роботи}

Дослідити відмінність концентрації кліндаміцину в лікворі при внутрішньовенному та комбінованому (інтратекально+внутрішньовенно) шляхах введення препарату.

\section{4. Матеріали та методи}

Дослідження проведено при лікуванні 11 ВІЛпозитивних пацієнтів віком від 27 до 63 років (5 чоловіків та 6 жінок) з токсоплазмозними менінгоенцефалітами.

Відбір зразків ліквору для першого (до початку інтратекальної терапії) вимірювання концентрації кліндаміцину проводився що найменше після 48-годинного внутрішньовенного введення кліндаміцину у дозі 600 мг×4 p/добу. Проводили люмбальну пункцію на рівні $\mathrm{L}_{3}-\mathrm{L}_{4}$ та відбирали 0,5-1,0 мл ліквору для дослідження. Після цього інтратекально вводили 150 мг. кліндаміцину та 8 мг дексаметазону. Відбір зразків ліквору для другого вимірювання концентрації поводили у того самого пацієнта через добу після інтратекального введення препаратів.

Дослідження з визначення концентрації кліндаміцину в лікворі проведені методом обернено-фазової високоефективної рідинної хроматографії (ВЕРХ) 3 ультрафіолетовим (УФ) детектуванням. Умови хроматографування градуювальних розчинів діючих речовин досліджуваного препарату та ліквору пацієнтів наведені у табл. 1.

Ідентифікацію діючої речовини (кліндаміцин) в зразках ліквору пацієнтів проводили за часом утримування в градуювальному розчині, кількісне визначення - за відповідною залежністю площі хроматографічного піку речовини від концентрації в градуювально- му розчині, яку встановлювали на підставі кореляційного та регресійного аналізів.

Таблиця 1

Умови хроматографування кліндаміцину

\begin{tabular}{|c|c|}
\hline $\begin{array}{c}\text { Хроматограф } \\
\text { Детектор }\end{array}$ & «Шимадзу» LC-20AD \\
\cline { 2 - 2 } Колонка & Ультрафіолетовий \\
\hline Рухома фаза & $\begin{array}{c}\text { Нуклеосил } \\
100-5 \text { С18 (250/4,6 мм) }\end{array}$ \\
\hline $\begin{array}{c}\text { Суміш ацетонітрил+ } \\
+0,1 \text { \% водний розчин } \\
\text { ортофосфорної кислоти }\end{array}$ \\
\hline $\begin{array}{c}\text { Співвідношення компонентів } \\
\text { рухомої фази, (об+об) }\end{array}$ & $35+65$ \\
\hline $\begin{array}{c}\text { Швидкість потоку } \\
\text { рухомої фази, мл/хв }\end{array}$ & 1,0 \\
\hline Довжина хвилі детектування, нм & 210 \\
\hline Температура колонки, ${ }^{\circ} \mathrm{C}$ & 30 \\
\hline Об'єм петлі інжектора, мкл & 20 \\
\hline $\begin{array}{c}\text { Час утримування } \\
\text { за даних умов, хв }\end{array}$ & $3,5 \pm 0,1$ \\
\hline
\end{tabular}

Статистична обробка отриманих даних проводилася з використанням критерію Уілкоксону.

\section{5. Результати дослідження}

Концентрація кліндаміцину в лікворі після інтратекального введення майже в усіх випадках перевищувала попередній рівень препарату (до інтратекального введення). Результати вимірювань наведені у табл. 2.

Таблиця 2

Результати вимірювання концентрації кліндаміцину у лікворі хворих

\begin{tabular}{|c|c|c|c|c|c|}
\hline $\begin{array}{c}\text { № п\п } \\
\text { пацієнта }\end{array}$ & $\begin{array}{c}1 \text {-й } \\
\text { вимір }^{1}\end{array}$ & $\begin{array}{c}2 \text {-й } \\
\text { вимір }^{2}\end{array}$ & Зміна & $\begin{array}{l}\text { Ранг } \\
\text { зміни }\end{array}$ & $\begin{array}{c}\text { Зна- } \\
\text { ковий } \\
\text { ранг } \\
\text { зміни }\end{array}$ \\
\hline 1 & 0 & 0 & 0 & - & - \\
\hline 2 & 0 & 22,0 & 22,0 & 1 & 1 \\
\hline 3 & 0 & 0 & 0 & - & - \\
\hline 4 & 0 & 448,13 & 448,13 & 5 & 5 \\
\hline 5 & 0,38 & 107,87 & 107,49 & 2 & 2 \\
\hline 6 & 0,5 & 371,93 & 371,43 & 4 & 4 \\
\hline 7 & 0 & 665,08 & 665,08 & 7 & 7 \\
\hline 8 & 1,83 & 684,47 & 682,64 & 9 & 9 \\
\hline 9 & 2,27 & 679,17 & 676,90 & 8 & 8 \\
\hline 10 & 1,63 & 326,05 & 324,42 & 3 & 3 \\
\hline 11 & 0,9 & 654,14 & 653,24 & 6 & 6 \\
\hline $\begin{array}{c}\text { Сума знако- } \\
\text { вих рангів } \\
\text { зміни W }\end{array}$ & \multicolumn{5}{|c|}{45} \\
\hline $\begin{array}{l}\text { Рівень зна- } \\
\text { чущості р }\end{array}$ & \multicolumn{5}{|c|}{$<0,01$} \\
\hline
\end{tabular}

Примітка:

I- Вміст діючої речовини у лікворі пачієнта до інтратекального введення, мкг/ $\mathrm{cm}^{3}$;

${ }^{2}$ - Вміст діючої речовини у лікворі пацієнта, після інтратекального введення, мкг/ $\mathrm{cm}^{3}$ 
Отримані результати свідчать про статистично значуще підвищення концентрації кліндаміцину в лікворі хворих через добу після інтратекального введення 150 мг. препарату. Встановлені у двох випадках нульові концентрації препарату в лікворі після інтратекального введення, на нашу думку, пояснюються особливостями ліквородинаміки пацієнтів (виразна лікворна гіпотензія) та пов'язаними з цим технічними складнощами при проведенні маніпуляції. Це не вплинуло на статистичну значимість отриманих результатів та загальні висновки, адже у більшості випадків (9 з 11) отримано різницю концентрацій кліндаміцину в лікворі при внутрішньовенному введенні та комбінованому (інтратекально+внутрішньовенно), яка склала

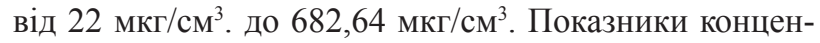
трації кліндаміцину у лікворі через добу після інтратекального введення перевищували попередній рівень препарату від декількох десятків до сотень разів. Логічно припустити, що відразу після введення концентрація кліндаміцину в лікворі була ще більшою.

В той же час у 5 випадках $з 11$ (45,5 \%), при дослідженні концентрації кліндаміцину у лікворі, лише після внутрішньовенного введення по 600 мг×4 рази на добу впродовж двох діб, препарату у спинномозковій рідині не виявлено. В решті випадків концентрація

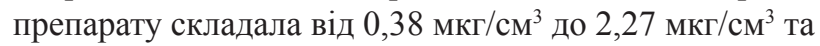
ймовірно залежала від важкості пошкодження гематоенцефалічного бар'єру в наслідок запального процесу, адже відомо, що при запаленні мозкових оболонок концентрація антибактеріальних препаратів в спинномозковій рідині значно зростає.

\section{6. Обговорення результатів}

Слід зазначити, що при безпосередньому лікуванні хворих з менінгоенцефалітами для лікуючого лікаря встановлення ступеню ушкодження гематоенцефалічного бар'єру майже завжди є не можливим. Тому, на підставі результатів отриманих в цьому дослідженні, вважаємо доцільним при призначенні кліндаміцину для лікування токсоплазмозних менінгоенцефалітів доповнювати традиційне внутрішньовенне введення препарату інтратекальним. Важливо відзначити, що в жодному випадку, після інтратекального введення 150 мг кліндаміцину з 8 мг дексаметазону, при наступному спостережені на протязі доби, не було зареєстровано будь-яких побічних явищ, що ще раз доводить безпечність запропонованого шляху введення препарату.

Крім того, отримані дані дають підстави рекомендувати комбіноване (інтратекально+внутрішньовенно) введення кліндаміцину для лікування менінгоенцефалітів, викликаних іншими чутливими до препарату мікроорганізмами.

Результати роботи підтвердили безпечність та довели статистично значуще підвищення концентрації кліндаміцину при інтратекальному шляху введення. Однак враховуючі невеликий об'єм проведеного дослідження та необхідність урахування кінцевого лікувального ефекту від запропонованого методу, необхідним є продовження клінічних досліджень у даному напрямку.
В той же час, у зв'язку з інвазивністю маніпуляції, проведення запропонованого методу терапії можливо лише досвідченими фахівцями, що мають навички боротьби з теоретично можливими ускладненнями, які загальновідомі при проведенні пункції інтратекального простору.

\section{7. Висновки}

1. Інтратекальне введення 150 мг кліндаміцину з 8 мг дексаметазону є безпечним.

2. Інтратекальне введення 150 мг кліндаміцину 38 мг дексаметазону в поєднанні з внутрішньовенним введенням препарату призводить до статистично значущого підвищення концентрації кліндаміцину в лікворі що найменше впродовж доби після ін'єкції.

3. Інтратекальне введення кліндаміцину з дексаметазоном у запропонованих дозах може бути рекомендованим для лікування менінгоенцефалітів, що викликані чутливими до кліндаміцину мікроорганізмами.

4. У разі початку терапії токсоплазмозного менінгоенцефаліту внутрішньовенним призначенням кліндаміцину, для підвищення ефективності, шляхом створення ефективної концентрації препарату у вогнищі інфекції, рекомендовано доповнення лікування інтратекальним введенням кліндаміцину з дексаметазоном у запропонованих дозах.

5. Інтратекальні методи терапії мають застосовувати фахівці відповідної кваліфікації.

\section{Література}

1 Недзьведь, М. К. Токсоплазмозный менингоэнцефалит у больных ВИЧ/СПИД (клиникоморфологический анализ) [Текст] / М. К. Недзьведь, Ю. И. Рогов, М. А. Метельская, Л. Н. Гришенкова, М. А. Иванова, И. В. Бохан // Здравоохранение. - 2012. - № 2. - С. 4-7.

2. Грижак, I. Г. Алгоритм діагностики токсоплазмозу у ВІЛ-інфікованих жінок репродуктивного віку та лікувальна тактика $[$ Текст] / I. Г. Грижак, Б. М. Дикий, О. Є. Кондрин, Р. С. Остяк, А. Л. Процик // Профілактична медицина. - 2012. - № 1. - С. 27-31.

3. Бартлетт, Д. Клинический подход к лечению ВИЧ-инфекции [Текст] / Д. Бартлетт, Д. Галлант. - Baltimore, 2003. $-394 \mathrm{c}$.

4. ДАЛАЦИН Цтм [Електроний ресурс]: інструкція, застосування препарату. - Режим доступу: |www/URL: http://mozdocs.kiev.ua/likiview.php?id=6537

5. Nau, R. Penetration of drugs through the blood-cerebrospinal fluid. Blood-brain barrier for treatment of central nervous system infections [Text] / R. Nau, F. Sörgel, H. Eiffert // Clinical Microbiology Reviews. - 2010. - Vol. 2, Issue 4. P. 858-883. doi: 10.1128/CMR.00007-10

6. Вашуков, С. А. Лечение и профилактика посттравматических менингитов [Текст] / С. А. Вашуков, А. С. Поляшов, В. Г. Порохин // Тез. докл. ҮІІІ Всерос. съезда анестезиол.-реаниматол. - Омск, 2002. - 96 с.

7. Кубраков, К. М. Интратекальное введение антибактериальных препаратов у нейрохирургических больных с менингоэнцефалитами [Текст] / К. М. Кубраков, А. Н. Косинец, А. В. Акуленок // Новости хирургии. - 2008. T. 16. - № 4. - C. 86-93. 
8. Царенко, С. В. Нейрореаниматология. Интенсивная терапия черепно-мозговой травмы [Текст] / С. В. Царенко. - М.: Медицина, 2006. - 352 с.

9. Berning, S. E. Novel treatment of meningitis caused by multidrug-resistant Mycobacterium tuberculosis with intrathecal levofloxacin and amikacin: Case report [Text] / S. E. Berning, T. A. Cherry, M. D. Iseman // Clinical Infectious Diseases. 2001. - Vol. 32, Issue 4. - P. 643-646. doi: 10.1086/318698

10. Борщов, С. П. Експериментальне дослідження безпечності інтратекального застосування кліндаміцину [Текст] / С. П. Борщов, І. В. Фільчаков, П. В. Сініцин, Н. М. Серединська // Профілактична медицина. - 2012. № 3-4. - C. 76-81.

\section{References}

1. Nedz'ved', M. K., Rogov, Ju. I., Metel'skaja, M. A., Grishenkova, L. N., Ivanova, M. A., Bohan, I. V. (2012). Toksoplazmoznyj meningojencefalit u bol'nyh VICh/SPID (klinikomorfologicheskij analiz). Zdravoohranenie, 2, 4-7.

2. Gryzhak, I. G., Dykyj, B. M., Kondryn, O. Je., Ostjak, R. S., Procyk, A. L. (2012). Algorytm diagnostyky toksoplazmozu u VIL-infikovanyh zhinok reproduktyvnogo viku ta likuval'na taktyka. Profilaktychna medycyna, 1, 27-31.

3. Bartlett, D., Gallant, D. (2003). Klinicheskij podhod k lecheniju VICh-infekcii. Baltimore, 394.
4. DALACYN CTM : instrukcija, zastosuvannja preparatu. - Available at: Iwww/URL: http://mozdocs.kiev.ua/likiview.php?id=6537

5. Nau, R., Sorgel, F., Eiffert, H. (2010). Penetration of Drugs through the Blood-Cerebrospinal Fluid/Blood-Brain Barrier for Treatment of Central Nervous System Infections. Clinical Microbiology Reviews, 23 (4), 858-883. doi: 10.1128/cmr.00007-10

6. Vashukov, S. A., Poljashov, A. S., Porohin, V. G. (2002). Lechenie i profilaktika posttravmaticheskih meningitov. Tez. dokl. YIII Vseros. s'ezda anesteziol.-reanimatol. Omsk, 96.

7. Kubrakov, K. M., Kosinec, A. N., Akulenok, A. V. (2008). Intratekal'noe vvedenie antibakterial'nyh preparatov u nejrohirurgicheskih bol'nyh s meningojencefalitami. Novosti hirurgii, 16 (4), 86-93.

8. Carenko, S. V. (2006). Nejroreanimatologija. Intensivnaja terapija cherepno-mozgovoj travmy. Moscow : Medicina, 352.

9. Berning, S. E., Cherry, T. A., Iseman, M. D. (2001). Novel Treatment of Meningitis Caused by Multidrug-Resistant Mycobacterium tuberculosis with Intrathecal Levofloxacin and Amikacin: Case Report. Clinical Infectious Diseases, 32 (4), 643-646. doi: 10.1086/318698

10. Borshhov, S. P., Fil'chakov, I. V., Sinicin, P. V., Seredins'ka. N. M. (2012). Eksperimental'ne doslidzhennja bezpechnosti intratekal'nogo zastosuvannja klindamicinu. Profilaktichna medicina, 3-4, 76-81.

Рекомендовано до публікаиії д-р мед. наук Задорожна В. I. Дата надходження рукопису 15.06.2015

Борщов Сергій Петрович, кандидат медичних наук, старший науковий співробітник, відділ інтенсивної терапії та детоксикації, ДУ «Інститут епідеміології та інфекційних хвороб ім. Л.В. Громашевського НАМН України», вул. Галицька 4, Київ, Україна, 04123

E-mail: borshchev@ukr.net

\section{УДК 616.31:614.253:[616.716.1: 616.216-002]:005}

DOI: $10.15587 / 2313-8416.2015 .47304$

\section{ПОПЫТКА СИСТЕМАТИЗАЦИИ РАЗЛИЧНЫХ ФОРМ ЯТРОГЕННЫХ ВЕРХНЕЧЕЛЮСТНЫХ СИНУСИТОВ}

\section{(ㄷ) С. Д. Варжапетян}

В статье схематично продемонстрированы результаты систематизации различных клинических форм ятрогенного верхнечелюстного синусита соматогенного происхождения. Стоматогенные верхнечелюстные синуситы ятрогенного происхождения включают в себя 5 форм заболевания. Это травматическая, медикаментозная, иммунно-токсическая, инфекиионно-аллергическая и смешанные формы. Описаны этио-патогенетические особенности данных форм. Приведень результаты компьютерно-томографического обследования верхнечелюстных синусов паџиентов с некоторыми из форм указанной патологии Ключовые слова: ятрогенный верхнечелюстной синусит, классификация гайморитов, клинические формы ятрогенного верхнечелюстного синусита

Aim of research. Systematization of the various forms of iatrogenic maxillary sinusitis of stomatogenic origin on the basis of its etiological and pathogenetic peculiarities.

Material and methods of research. On the basis of results of the clinical analysis of the cases of inflammatory injuries of maxillary sinusitises of stomatogenic nature and the data of literature there was realized a distribution of the various forms of iatrogenic sinusitis of the stomatogenic origin into separate groups of the united classification. Results of research. Iatrogenic maxillary sinusitises of stomatogenic origin include 5 clinical forms: traumatic, medicamental, immune-toxic, infection-allergic and the mixed one.

Each clinical form of iatrogenic sinusitis has its etio-pathogenetic peculiarities.

Conclusions. It is necessary to study the pathologic changes in the mucous membrane of the maxillary sinus at the certain forms of iatrogenic maxillary sinusitis

Keywords: iatrogenic maxillary sinusitis, classification of maxillary sinusitises, clinical forms of iatrogenic maxillary sinusitis 